\title{
Uso de software no ensino-aprendizagem de Matemática
}

\author{
Eduardo Melloni Lucchesi* \\ Susana Seidel**
}

Resumo: relato de experiência ocorrida durante disciplina do curso de licenciatura em matemática da UFRGS, realizada no Colégio de Aplicação - Projeto Amora, visando a utilização de diferentes software como recursos no ensino-aprendizagem de matemática. $O$ trabalho foi organizado em Oficinas de Software, para as quais os alunos foram selecionados por suas próprias escolhas, após breve demonstração de cada programa. Os software utilizados foram: Cabri, X-Home, Shapari, Flash, Legocad e Imagine. Escolhidos por permitirem trabalhar com os conceitos de geometria plana e espacial, aritmética, transformações geométricas, assim como, raciocínio lógico e abstrato. Encontramos problemas com o uso dos recursos de informática e buscamos justificativas e soluções dentro das possibilidades que dispúnhamos.

Palavras - chave: software na aprendizagem, conceitos matemáticos, dificuldades e soluções.

Title: Software use in the teaching-learning of Mathematics

Abstract: report of experience happened during discipline of the licenciatura course in mathematics of UFRGS accomplished in the School of Application - Project Mulberry, seeking the use of different software as resources in the mathematics teaching-learning. The work was organized in Shops of Software, for which the students were selected by its own choices after brief demonstration of each program. The used software were: Cabri, X-Home, Shapari, Flash, Legocad and Imagine. Those were chosen for they allow to work with the geometry concepts it planes and space, arithmetic, geometric transformations, as well as, logical and abstract reasoning. We found problems with the use of the computer science resources and we looked for vindicative and solutions inside of our limitations. All this appears told and explained in this work.

Key - words: software on learning, mathematical concepts, difficulties and solutions.

\footnotetext{
*Engenheiro Eletricista; e-mail: eml7171@yahoo.com.br

** Estudante de Licenciatura em Matemática da UFRGS, no $5^{\circ}$ semestre; bolsista no programa ECSIC (Escola, Conectividade, Sociedade da Informação); e-mail: susanaseidel@yahoo.com.br
} 


\section{Introdução}

Através do relato das experiências que presenciamos com alunos do ensino fundamental do Colégio de Aplicação - Projeto Amora, temos como objetivo tornar conhecidas as principais dificuldades e as soluções encontradas quando se pretende aplicar uma metodologia de trabalho diferente da que se está acostumado a ver atualmente nas escolas. Por diferente aqui, queremos nos referir a substituição do tradicional material concreto por um material digital/virtual, a saber, utilização de internet e correio eletrônico, software matemáticos ou outros software, que oportunizem a aplicação dos conhecimentos matemáticos formais adquiridos na sala de aula, para solução de situações-problema elaborados por estudantes de graduação do Curso de Licenciatura em Matemática da UFRGS.

Dividimos esse relato, de forma a torná-lo mais claro, em duas partes, quais sejam, as dificuldades que encontramos na criação-aplicação do material digital/virtual e na experiência/reação propriamente dita da criança diante do que lhe é apresentado. Consideramos também que, ficaria mais objetivo, se estas partes fossem apresentadas em forma de tópicos seguindo a ordem cronológica do processo que utilizamos na Escola.

É importante mencionar que, pelo menos para quase todos, esta foi a primeira experiência em sala de aula como professores. Não se trata de justificar os erros cometidos, mas de identificar que o nosso aprendizado era simultâneo ao das crianças. Tínhamos liberdade para a elaboração das aulas desde que seguíssemos a proposta de que todo material produzido por nós ou pelos alunos fosse desenvolvido e publicado via mídia digital.

Com o intuito de que o material produzido sirva para que, compreendendo melhor como funciona o processo de ensino-aprendizagem, pelo menos nesse microcosmo que atuamos, possamos retirar elementos suficientes para intervir nele de forma cada vez mais lúcida, pois são os alunos que nos ensinam a nos tornarmos professores.

\section{Material e Métodos}

Essas práticas foram realizadas uma vez por semana, entre agosto e dezembro de 2003, no laboratório de informática do Colégio de Aplicação da UFRGS, com alunos de $5^{\mathrm{a}} \mathrm{e}$ $6^{a}$ séries. Enquanto cursávamos a disciplina de Laboratório de Prática de Ensino em Matemática I. O objetivo da disciplina é o de proporcionar um primeiro contato com estudantes do ensino fundamental para futuros professores de Matemática em experiências de prática de ensino e de solidificar conhecimentos adquiridos na sala de aula pelos alunos, especificamente relacionados a matemática e, no nosso caso, também com conhecimentos básicos de informática.

Os graduandos são divididos em dois grupos: aqueles que formarão as Assessorias de Matemática e que preparam suas atividades utilizando apenas material concreto, e, os que formarão as Assessorias de Interação Virtual (iv), da qual fazíamos parte, utilizando recursos de informática (software). Cada assessoria é subdividida em dois grupos, um grupo trabalha na segunda-feira (iv2) e o outro na quinta-feira (iv5) e, tendo em vista isso, o planejamento dos grupos não é, necessariamente, igual. 
Em nossas atividades de iv, utilizamos ferramentas e recursos de cada programa, conforme o conteúdo que se desejava abordar. Ou seja, a matemática era abordada a partir do próprio software e no raciocínio necessário para o uso desse. Os software utilizados nas aulas foram: Logo, Cabri, X-Home, Shapari, Legocad, Flash, Imagine e Poly. Como haviam dois grupos de iv independentes, os programas não foram igualmente usados.

O planejamento das aulas de cada grupo tornou-se mais independente com o passar do tempo, tendo cada turma uma atividade visando melhor ajudar seus alunos. Para melhor discutir as sugestões, as idéias que surgiam durante os encontros marcados fora do horário da aula, eram enviadas por e-mail para uma lista eletrônica comum a todos. Cada aula era discutida com o professor da disciplina, em busca de críticas e sugestões, que monitorava o processo via lista eletrônica no planejamento e durante as aulas. Também foram criadas duas páginas na internet ${ }^{1}$ contendo as atividades do dia, e possibilitando aos alunos acesso o material a qualquer momento e de qualquer lugar. Além disso, cada grupo (iv2 e iv5) criou um e-mail próprio ${ }^{2}$, ao qual todos os integrantes daquele grupo tinham acesso, para recebimento do material produzido pelo aluno, bem como de suas sugestões, críticas e de seus relatórios (relatos pessoais sobre cada aula, com reflexões sobre o que foi estudado e realizado). Portanto, as trocas ocorreram entre todos, graduandos, o nosso professor e os nossos alunos.

\section{Principais dificuldades observadas}

1. Criar situações-problema utilizando software, de forma que não pudessem ser realizadas com material concreto;

2. Criar um procedimento que otimizasse a relação entre número de professores e número de alunos;

3. Diferenças cognitivas dos alunos, tanto em relação à informática quanto à matemática;

4. Os diferentes interesses dos alunos quanto as atividades propostas e quanto aos diferentes software utilizados;

5. Planejamento de atividade específica a um determinado software, ou seja, encontrar a matemática no software e procurar explorar da melhor maneira possível os conceitos matemáticos existentes nele;

6. Pouca experiência dos graduandos no momento de colocar as idéias em prática;

7. O longo intervalo entre as aulas limitava algumas atividades;

8. Quebra na sequiência de algumas atividades por cancelamento de aulas por fatores involuntários, prejudicando a continuidade das atividades.

\section{Desenvolvimento do trabalho}

O início das aulas foi um pouco difícil pois não conhecíamos os alunos e suas dificuldades. Pensamos em criar algum desafio que interessasse aos alunos, utilizando algum (até então, qualquer um) software, de forma que não fosse possível fazê-lo com material concreto(D1) ${ }^{\mathbf{3}}$. Não foi muito complicado ter idéias, a maior dificuldade ficou no acabamento da atividade, pois durante a aplicação é que notávamos um detalhe ou 
outro que deveria ser mudado, retirado ou acrescentado para que a proposta que tivesse o alcance pretendido.

A primeira aula não foi exatamente como gostaríamos, mas funcionou. Os alunos foram receptivos. Afinal o computador "prende" a atenção das pessoas, talvez por isso eles não tenham ficado tão inquietos. Com o passar das aulas, começamos a ouvir reclamações, tais como: "Esse programa de novo?" ou "Por que vocês não trazem o programa "tal" para a gente trabalhar?", entre outras. Começamos a perceber as diferenças entre os alunos(D4). Enquanto em uma determinada aula vários alunos estavam gostando da atividade e do software, outros estavam detestando tudo ou, pelo menos, o programa escolhido. Ou seja, não existia diferença apenas no fato de uns gostarem e outros não da atividade, também era possível notar diferença na aprendizagem deles(D3). Algumas vezes determinada aula não era apreciada por um aluno que a considerava muito fácil, já para outro, exigia maior empenho e atenção pois aquilo era difícil(D3). Agradar e fazer uma aula acessível a todos não é possível, mas queríamos melhorar o nosso planejamento o quanto pudéssemos(D6). Constatamos que não havíamos nos organizado para acompanhar mais de perto um grupo de alunos específico(D2), prejudicando a avaliação de suas eventuais dificuldades e preferências, para poder assim, tomarmos atitudes compensatórias necessárias as citadas individualidades cognitivas.

Então, pensamos em preparar a aula utilizando o software com o qual eles gostariam de trabalhar, para que se interessassem e aprendessem mais, afinal, haveria um interesse legítimo(S4/S3) ${ }^{4}$. De que forma então, decidir por um único programa, considerando todas as diferenças envolvidas? Discutindo o assunto, surgiu-nos a idéia das Oficinas de Software(S6/S1). Funcionaria da seguinte maneira: dividiríamos os alunos segundo sua opção por um dos software sugeridos por nós. A divisão seria feita por preferência pessoal, conhecimento e facilidade com um determinado programa. Criando as Oficinas, agrupamos crianças e granduandos, obtendo uma forma de acompanhá-los individualmente quanto as suas dificuldades e eliminamos a rejeição por software específico.

Temos aqui uma diferença entre a iv2 e a iv5. Na iv2, as Oficinas foram implantadas após algumas aulas, enquanto na iv5 iniciaram após dois meses de aula. A iv5 apresentava problemas semelhantes aos da iv2, mas, com uma menor rejeição aos software e as propostas, até então, utilizados nas aulas. Devido a dificuldades entre os graduandos por mudança freqüente dos componentes do grupo, o planejamento das aulas ficou prejudicado, repercutindo no trabalho em sala de aula. O que, por si só, já seria motivo suficiente para criação das Oficinas na iv5. Além disso, as crianças da quinta-feira tomaram conhecimento dos software utilizados na segunda-feira e começaram a solicitar também a variedade de programas que a Oficina de Software apresentava.

Uma idéia que surgiu a partir das oficinas, foi pedir aos alunos que fizessem projetos ao final da oficina da qual participavam, com o intuito de incentivá-los a aprender e desafiá-los a fazer algo novo, que eles mostrariam a todos os professores e colegas ao final do ano. O projeto seria uma construção feita no software trabalhado na Oficina, com liberdade de escolha do aluno sobre o tema, utilizando as ferramentas exploradas e conhecimentos obtidos durante as aulas. Em todas as oficinas, foram feitos projetos, alguns mais complexos, outros menos. $\mathrm{Na}$ iv2, os projetos foram deixados para um 
segundo momento, para que num primeiro conceitos de matemática fossem trabalhados. A não ocorrência de algumas aulas coincidiu com a época dos projetos(D8), prejudicando um pouco, mas não impedindo, o seu desenvolvimento, dadas as diferenças de cada software quanto à complexidade das animações. Nesse ponto, não tivemos como contornar a situação. Apenas tentamos ajudar ao máximo, para que os alunos pudessem fazer o melhor projeto possível no tempo disponível. No geral, os projetos foram bons e serviram, também, para mostrar o quanto eles aprenderam sobre o software, o quanto estavam dominando as ferramentas ao final do ano. Isso pôde ser notado durante as apresentações dos projetos, quando tivemos a oportunidade de ouvir os alunos falarem o que haviam aprendido, muitos deram explicações de como construíram seus projetos e como usaram os software. Alguns falaram sobre coordenadas, ângulos, figuras planas e animação, com a maior naturalidade, já que era o assunto nas aulas. Foi surpreendente aos graduandos ouvi-los falar sobre isso, e nesse momento nos demos conta do que eles haviam entendido das aulas e o quanto pudemos auxiliá-los.

Com as oficinas, cada um de nós tornou-se responsável por um determinado número de alunos e a nossa dificuldade de conhecê-los foi solucionada(S2). Agora, deveríamos nos concentrar em atividades que fossem ajudar a aqueles alunos. Bom, neste momento criou-se um desafio para nós: tínhamos o software com o qual iríamos trabalhar e deveríamos criar atividades utilizando apenas ele e seus recursos. Por causa disso, cada grupo de graduandos de cada oficina, passou a fazer seu próprio planejamento, mas a reunião geral, imediatamente ao final de cada aula para que todos pudessem participar, continuou acontecendo. Nessa reunião, apontava-se as dificuldades daquela aula, possíveis soluções e iniciava-se a elaboração da atividade seguinte. Todos (Matemática e Interação) se reuniam para discutir problemas, mas com o tempo achamos mais produtivo realizar o planejamento separadamente. Trocávamos experiências, aulas que deram ou não certo, mas cada um passou a se dedicar ao planejamento a partir de programa que usava.

\section{Oficina de Cabri / iv2}

Nessa oficina, obtivemos bons resultados de aprendizagem com os nossos alunos. Utilizando o Cabri, tivemos a oportunidade e a possibilidade de trabalhar conceitos matemáticos tais como: definições e noções de geometria plana, cálculo de área, ângulos, número Pi. Também deve-se destacar que os alunos tiveram a oportunidade de aprender a utilizar melhor os recursos do software, sem falar do raciocínio necessário a cada construção.

Apesar de já ser conhecido pelos alunos e utilizado por outros professores, nenhum aluno tinha maior domínio do software no início das oficinas, apenas conheciam alguns recursos básicos. Como o Cabri é um programa específico para geometria plana, procuramos iniciar as aulas com atividades nesse sentido. Pedimos que construíssem figuras planas utilizando ferramentas do programa, algumas conhecidas por eles e outras indicadas e explicadas por nós. Inicialmente queríamos saber o quanto eles conheciam de geometria, mais especificamente sobre triângulos - nomes, definições. Então pedimos que construíssem aqueles que conheciam, dissessem seus nomes e relacionassem suas diferenças. Notamos que eles até conheciam os nomes mas não as diferenças. Nesse momento, foi muito bom estar usando o Cabri, pois eles podiam 
medir os segmentos, os ângulos para se darem conta dessas diferenças. Outras figuras como quadrado, retângulo e polígonos regulares também foram construídas e estudadas. A seguir, trabalhamos com circunferências, suas medidas e algumas definições. Eles não conheciam o conceito de diâmetro, apenas tinham uma noção sobre raio. Após apresentar essas medidas, passamos para os cálculos de áreas, iniciando pelas primeiras figuras trabalhadas (triângulos, retângulos...) e depois passando para o cálculo da área da circunferência. Nesse ponto, foi necessário apresentar a eles o número Pi - como foi calculado, quanto vale - para possibilitar os cálculos. No caso das primeiras figuras, procuramos deixá-los darem-se conta de como se calcula a área e a maioria deles já havia aprendido alguma fórmula, ou seja, eles já sabiam como calcular, mas no caso da circunferência, informamos a fórmula.

A cada construção, pedíamos que fizessem animações. No começo, como as construções eram muito simples, apenas uma ou duas figuras, não havia muito a ser animado. Mas, com o passar das aulas, eles foram fazendo construções mais complexas, utilizando várias figuras, regulares ou não, podendo então utilizar essas animações. As construções mais comuns eram relacionadas a figuras do dia-a-dia deles, como carros, pessoas, sol. Foi um dos momentos em que as aulas tiveram por objetivo ensinar a utilizar o software, no caso, a animar as construções. Mas para animar, no Cabri, é necessário que as figuras estejam interligadas, que sejam dependentes. Por isso, nas construções utilizam-se retas perpendiculares e paralelas quase o tempo todo, para manter uma relação entre os objetos. Por causa disso, pudemos abordar ângulos, retas e diferença entre reta e segmento.

A criação de projetos pelos alunos, idéia surgida no início das Oficinas, tornou-se outro incentivo ao trabalho das crianças. Os alunos procuravam aprender como utilizar os recursos do programa para usá-los nos seus projetos. Por motivo de falta de aulas (ver item $4,3^{\circ}$ parágrafo), tivemos pouco tempo para os projetos e os alunos ficaram um pouco chateados por não terem tido tempo para fazer um projeto como gostariam. Essa foi a nossa frustração com as Oficinas.

Enfim, com uma atividade levando a outra e cada necessidade abrindo possibilidades, foi feita a Oficina. Provavelmente, as dificuldades e os desafios encontrados geraram idéias e soluções criativas. Os alunos ficaram mais motivados em trabalhar com algo que gostavam, mas nós também estávamos sendo desafiados, talvez isso tenha nos ajudado a procurar cada vez mais encontrar matemática naquele software e conseguir, assim, passar os conceitos matemáticos aos alunos de forma diferente à tradicional.

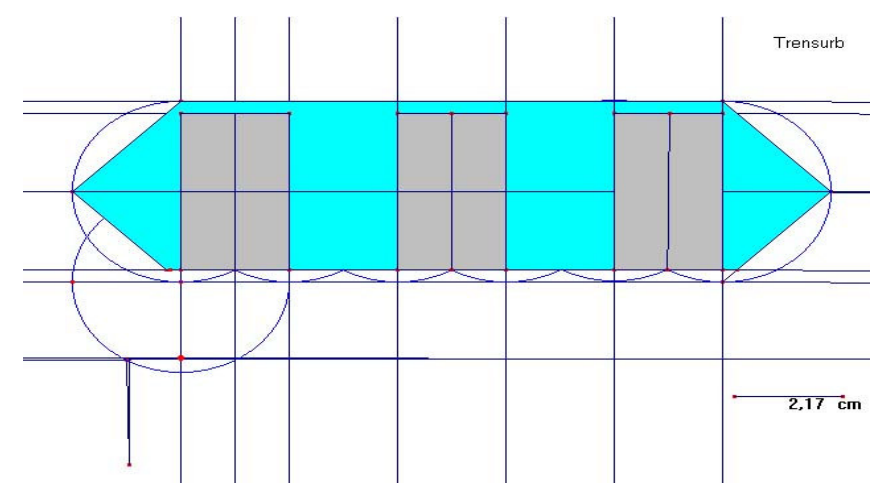




\section{Projeto de um dos alunos da Oficina de Cabri / iv2}

Neste projeto o aluno construiu um trem, lembrando o trensurb, utilizando circunferências, retas perpendiculares e paralelas, segmentos, polígonos, transferência de medidas, compasso, preenchimento de polígonos entre outros. Usou ferramentas do software e trabalhou com conceitos matemáticos, tais como: raio (observando que o raio de todas as circunferências do projeto é igual a $2,17 \mathrm{~cm}$ podendo variar igualmente por manipulação), ângulos, retas, polígonos regulares e medidas. Ele teve o auxílio das professoras da oficina, mas teve autonomia na produção do projeto. Recebia explicações sobre as ferramentas que poderia e deveria usar e exemplos de utilização. Esse aluno foi um dos que citou, durante a apresentação, conceitos matemáticos. Pela imagem se nota as possibilidades de exploração de matemática desse projeto.

Para ver outros projetos do grupo iv2, acesse: http://matematicao.psico.ufrgs.br/iv2/

\section{Oficina de Flash / iv5}

O Flash, relativamente aos outros software utilizados nas oficinas, é o programa que apresenta maior complexidade para seu entendimento e sua utilização. A grande variedade de recursos e de ferramentas o torna mais flexível, permite maiores possibilidades e justamente por esses recursos, é o que exige equipamentos melhores para um bom trabalho.

Desperta, por seus recursos, maior interesse nos usuários comuns e em situações de ensino-aprendizagem, exigindo naturalmente maior dedicação e envolvimento dos que optaram por ele. Além disso, não é um software específico para trabalhar matemática, exigindo também mais nas criação de atividades a serem desenvolvidas nele.

Levando em consideração as possíveis dificuldades de uso e para que as crianças ganhassem confiança e chegassem a uma relativa independência no Flash, iniciamos as atividades através de uma espécie de mini-curso. Em duas aulas, o mini-curso começava com as construções mais básica de desenho apresentadas passo-a-passo em páginas publicadas na internet para esse propósito ${ }^{5}$. Na segunda já eram propostos alguns desafios conceituais de geometria (circunferências, quadrados, profundidade, perspectiva), transformações geométricas(simetria, translação, rotação, escala), sistema de eixos e de animação.

Como teríamos poucas aulas mais para trabalhar, resolvemos começar logo com os projetos pessoais e na medida do possível ir abordando conceitos matemáticos. Nem todos os projetos ensejavam os mesmos conceitos matemáticos, mas justamente pelo material ser publicado na Internet, é que todos podem se beneficiar das experiências de todos os outros pelas trocas síncronas e assíncronas.

A já mencionada complexidade do programa, levou, em alguns poucos casos, a troca na escolha da Oficina. Diante dos desafios que exigiam maior envolvimento e perseverança, ainda no começo da Oficina, algumas delas optaram por trocar de software, sendo então remanejadas, sem que isso causasse problemas no andamento do trabalho. Tivemos problemas de continuidade no acompanhamento dos projetos, por causa do cancelamento de algumas aulas. $O$ que acarretou de nossa parte, uma 
intervenção maior da que gostaríamos, no processo de aprendizagem, para que os projetos pudessem ser finalizados.

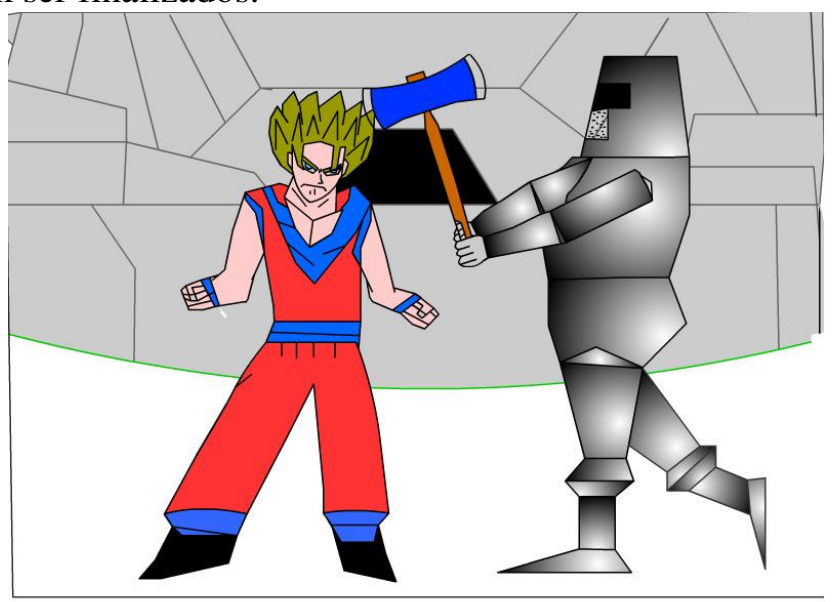

\section{Trabalho publicado em http://matematicao.psico.ufrgs.br/iv5/projts/final.htm/}

A imagem acima ilustra um dos projetos publicados ${ }^{6}$. Cada um dos personagens ilustrados seria o objeto de projeto de um aluno diferente. Pela falta de tempo e problemas com algumas máquinas os projetos foram fusionados criando um interessante duelo entre uma criatura medieval e um personagem dos futuristas desenhos japoneses. Em cada um deles vários elementos são destacáveis e podem melhor ser ilustrados vendo-se a animação completa. Existe, no personagem da esquerda, transformações de escala, pois ele muda de tamanho continuamente enquanto a cor de seu cabelo vai mudando. Já no personagem da direita, existe uma rotação que foi aplicada aos golpes de machado, noções de profundidade em partes do corpo que estão na frente de outras não foram feitas mas que foram observadas pelos autores da obra em questão.

\section{Conclusão}

Essa experiência foi importante para os graduandos pois, além de ser um primeiro contato com alunos, fomos desafiados a criar procedimentos que ajudem os alunos a aprender matemática. Todos tivemos que estudar e conhecer melhor os programas, para percebermos o que nele poderia ser utilizado. Com o passar das aulas, essa tarefa foi parecendo mais fácil, já que além de aprender matemática, os alunos deveriam aprender a usar os programas também. Quanto mais eles soubessem, mais poderíamos explorar a matemática.

Para o próximo semestre, 2004/1, pretendemos continuar com o trabalho em oficinas pois acreditamos que ele apresenta possibilidades de exploração efetivas. Os resultados obtidos foram bons, podendo ser melhor aproveitados a medida que tenhamos maior conhecimento dos software, da matemática em si e do processo de ensino-aprendizagem. Mas, uma coisa poderia ser diferente dessa vez: trabalhar em apenas um software todo o tempo não foi a melhor atitude nas oficinas. Isso porque, após um tempo de trabalho, já não se tem mais muita matemática para explorar e as aulas ficam pobres. Poderíamos apenas trabalhar conceitos mais avançados da matemática, o que não é possível dada a fase de desenvolvimento das crianças. Poderíamos fazer troca de software na metade das aulas, assim, teríamos mais conceitos 
a abordar e os alunos teriam a oportunidade de trabalhar dois programas diferentes. Outra coisa a ser estudada, pelo grupo de graduandos que cursarão a disciplina, é a possibilidade de utilizar outros software, diferentes dos utilizados neste ano que passou. Poderíamos procurar outros ainda não conhecidos pelos alunos. Esta é uma maneira de nos preocupando com a aprendizagem dos alunos, assim como com a nossa própria aprendizagem e capacitação para o uso de recursos de informática no ensinoaprendizagem de matemática.

Tivemos a oportunidade de aprender a termos maior responsabilidade com nossas tarefas. Foi uma primeira experiência com alunos, suas opiniões e críticas. Tivemos que nos dedicar, tanto na preparação de material para as aulas, como também no estudo dos software. Os graduandos também aprenderam bastante sobre os programas e, principalmente, tiveram que usar a criatividade e seus conhecimentos já adquiridos de matemática para formular as aulas. Com certeza, esse último semestre foi uma ótima experiência e uma boa aprendizagem.

Apesar de termos tido dificuldades na implantação de algumas idéias, de um modo geral, conseguimos ajudar os alunos na aprendizagem de matemática. Talvez algumas coisas pudessem ter sido diferentes, mas não tivemos muito tempo para mudar, o que está incluído na nossa próxima experiência. Apesar dos problemas, consideramos a experiência produtiva e bastante válida, tanto para nós quanto para os alunos. Assim como eles, nós aprendemos durante a preparação e a aplicação das idéias. Muito mais do que "dar aula", nós estamos aprendendo com eles a ensinar. Passamos a conhecer melhor como é estar com alunos e ter a responsabilidade de ajudá-los. Para muitos graduandos, essa, foi mais que uma disciplina, foi uma verdadeira experiência como professores. Também devemos continuar estudando e nos preparando, para podermos utilizar a informática como nossa aliada e, cada vez mais, auxiliar aos alunos no ensinoaprendizagem de matemática, nosso maior objetivo. 


\section{Notas do Texto}

1. Página do grupo iv2: http://matematicao.psico.ufrgs.br/iv2 e página do grupo iv5 http://matematicao.psico.ufrgs.br/iv5;

2. e-mail dos grupos: iv2@psico.ufrgs.br e iv5@psico.ufrgs.br;

3. D1: indica dificuldade 1 referente a lista apresentada no item 3;

4. S1: indica solução ao desfio 1;

5. Mini-curso de Flash: http://matematicao.psico.ufrgs.br/iv5/1016/index.html;

6. Para ver outros projetos do grupo iv5, acesse: http://matematicao.psico.ufrgs.br/iv5/.

\section{Bibliografia}

FAGUNDES, Léa da Cruz. Aprendizes do futuro: as inovações começaram. Coleção Informática para a Mudança na Educação. MEC/ SEED/ ProInfo, 1999.

Tese de Doutorado do Professor Marcus Vinícius de Azevedo Basso. Disponível em: http://lec.psico.ufrgs.br/ mbasso/tese/Acessado em: fevereiro/2004

PROJETO AMORA, desenvolvido pelo Colégio de Aplicação da UFRGS desde 1996.

Disponível em : http://amora.cap.ufrgs.br. Acessado em: dez/2002. 